\title{
COVID-19 anticuerpos IgM/IgG por ensayo inmunocromatográfico (prueba rápida)
}

\section{COVID-19 IgM/IgG antibodies by immunochromatographic assay (rapid test)}

\author{
Jennifer C. Vizcaíno-Carruyo', Verónica J. Tangarife-Castaño², \\ Germán Campuzano-Zuluaga ${ }^{3}$, Ana Isabel Toro-Montoya ${ }^{4}$
}

\section{Utilidad clínica de la prueba}

Las pruebas serológicas son de gran apoyo para el diagnóstico de la enfermedad por coronavirus 2019 (COVID-19), causada por el virus SARS-CoV-2. La prueba serológica basada en inmunocromatografía (también conocida como prueba rápida), disponible en nuestro medio, detecta la presencia de anticuerpos tipo IgM e IgG, generados como respuesta a la infección. Los anticuerpos IgM comienzan a ser detectables en la sangre después de la primera semana de iniciada la infección (etapa intermedia) y perduran por 2 ó 3 semanas, en tanto que los anticuerpos lgG aparecen en la etapa tardía, que ocurre generalmente después de la segunda semana, y perduran en el tiempo. Debido a que las pruebas moleculares, basadas en la técnica de la reacción en cadena de la polimerasa con transcriptasa reversa (RT-PCR), detectan el genoma viral, estas pueden arrojar resultados negativos en las etapas tardías de la infección, por lo que el uso conjunto de las pruebas moleculares con las serológicas, aumenta de manera significativa la capacidad diagnóstica para COVID-19.

\footnotetext{
${ }^{1}$ Médica, Especialista en Hematología. Asistente Científica, Editora Médica Colombiana S.A. Medellín, Colombia.

${ }^{2}$ Microbióloga y Bioanalista. MSc en Ciencias Básicas Biomédicas. Coordinadora de Investigación, Desarrollo y Academia.

Laboratorio Clínico Hematológico S.A., Editora Médica Colombiana S.A. Medellín, Colombia.

${ }^{3}$ Médico, Especialista en Patología Anatómica y Clínica, Subespecialista en Hematopatología. Fellow, College of American Pathologists (FCAP). Director, Laboratorio Clínico Hematológico S.A. Director, Editora Médica Colombiana S.A. Medellín, Colombia

${ }^{4}$ Bacterióloga y Laboratorista Clínica. MSc en Virología. Directora Científica, Editora Médica Colombiana S.A. Medellín,

Colombia.E-mail: atoro@edimeco.com.
} 


\section{Fundamento de la técnica}

Esta prueba es un inmunoensayo cromatográfico de flujo lateral, para la detección cualitativa de anticuerpos IgM e IgG contra el virus SARS-CoV-2. El dispositivo está compuesto por una membrana de nitrocelulosa, recubierta en uno de sus segmentos con proteína recombinante del virus, a la cual se unen los anticuerpos lgM y/o lgG, específicos para SARS-CoV-2, en la muestra del paciente, de estar presentes. El dispositivo incluye un pozo donde se deposita la sangre del paciente, y otro pozo donde se adiciona una solución con un conjugado de anticuerpos de ratón (anti-lgM y anti-lgG humanas) y partículas de oro coloidales, que se fijarán a los anticuerpos en la muestra del paciente, si están presentes. En estos casos, se forma un complejo anticuerpo-anticuerpo, que migra en la membrana por acción capilar, y que va a reaccionar con la proteína recombinante del SARS-CoV-2, adherida a la membrana, dando un resultado positivo después de 15 minutos de incubación, el cual aparece en el dispositivo como una línea de color violeta. La intensidad del color varía con la cantidad de anticuerpos presentes en la muestra del paciente. De manera similar, hay otro segmento del dispositivo que sirve como control de la prueba, el cual tiene una línea que debe siempre aparecer visible, si la prueba fue realizada de manera satisfactoria.

\section{Muestra y almacenamiento}

La muestra puede ser suero, plasma o sangre total venosa. Las muestras de suero o plasma se pueden utilizar hasta una semana después de extraídas, en los tubos de ensayo correspondientes, conservadas en refrigeración $\left(2^{\circ} \mathrm{C}\right.$ a $\left.8^{\circ} \mathrm{C}\right)$; para un almacenamiento prolongado, deben congelarse por debajo de $-40^{\circ} \mathrm{C}$.

\section{Procedimiento}

Se recolectan $10 \mu \mathrm{L}$ de sangre con una micropipeta, y se dispensa en el pozo asignado para la muestra del paciente, en el dispositivo para la prueba. Luego se agregan 3 gotas $(90 \mu \mathrm{L})$ de la solución con el conjugado en el pozo correspondiente. El resultado se lee entre los 10 y 15 minutos posteriores; una lectura después de pasados 15 minutos puede arrojar un resultado inválido.

\section{Interpretación de los resultados}

Para demostrar que la prueba está funcionando correctamente, debe aparecer una banda de color violeta en el segmento donde está la línea para el control " $\mathrm{C}$ ". Si el resultado es positivo, aparecerá una línea adicional, también de color violeta, en el segmento con las líneas de prueba "M" (para la lgM) o "G" (para la lgG), o ambas (tabla 1).

\section{Limitaciones y ventajas de la prueba}

Esta prueba no se recomienda usar como criterio único para el diagnóstico de infección por SARS-CoV-2. Se debe tener presente que un resultado negativo no descarta la infección por el virus, en particular en las etapas iniciales de la infección, cuando aún no son detectables los anticuerpos contra el virus. En cualquier caso, el manejo de los algoritmos diagnósticos para COVID-19 lo debe hacer el médico tratante que, en conjunto con los hallazgos clínicos y epidemiológicos, pueda interpretar los resultados de las pruebas y seguir las conductas médicas más indicadas.

Cuando la prueba se realiza después de la primera semana de la infección 
Tabla 1. Interpretación clínica de la prueba para detectar anticuerpos contra SARS-CoV-2

\begin{tabular}{ccc}
\hline \multicolumn{2}{c}{ Anticuerpo } & \\
\cline { 1 - 2 } IgM & IgG & Interpretación clínica \\
\cline { 2 - 3 }+ & - & Etapa temprana o ausencia de infección \\
- & + & Etapa intermedia y activa de la infección \\
+ & + & Etapa tardía o de recuperación de la infección, pero aún activa \\
\hline
\end{tabular}

inicial, puede alcanzar una sensibilidad y una especificidad cercanas al 100\% (tabla 2). Es una prueba que fue validada por el Instituto Nacional de Salud (INS), de acuerdo a los re- querimientos del Ministerio de Salud y Protección Social del país. Los resultados se obtienen en tan solo $20 \mathrm{mi}$ nutos, y no requiere que el paciente esté en ayunas.

Tabla 2. Desempeño diagnóstico de la prueba

\begin{tabular}{cccc}
\hline Anticuerpo & $\begin{array}{c}\text { Días después } \\
\text { de RT-PCR }\end{array}$ & Sensibilidad* & Especificidad* \\
\hline IgM & 7 & $91,7 \%$ & $\sim 100 \%$ \\
\hline $\lg$ & 7 & $\sim 100 \%$ & $\sim 100 \%$ \\
& 12 & $79,2 \%$ & $\sim 100 \%$ \\
\hline
\end{tabular}

\footnotetext{
*Ninguna prueba serológica se considera que tiene un $100 \%$ de sensibilidad o especificidad, y existe la posibilidad de resultados falsos positivos y falsos negativos, aunque baja, que deben ser considerados en algunos casos, según los hallazgos clínicos del paciente.
}

\section{Referencias}

1. SD Biosensor. Standard Q COVID-19 lgM/lgG Duo. Ref Q-NCOV-01D. Republic of Korea: SD Biosensor; 2020. Acceso 19 de junio de 2020. Disponible en http://sdbiosensor.com/xe/product/7662.

2. Díaz-Castrillón FJ, Toro-Montoya Al. SARSCoV-2/COVID-19: el virus, la enfermedad y la pandemia. Med Lab 2020;24:183-205. https:// doi.org/10.36384/01232576.268.
3. Guo L, Ren L, Yang S, Xiao M, Chang D, Yang F, et al. Profiling early humoral response to diagnose novel coronavirus disease (COVID-19). Clin Infect Dis 2020; published online 21 March 2020. https://doi.org/10.1093/cid/ciaa310.

4. Zhao J, Yuan Q, Wang $H$, Liu W, Liao $X$, Su $\mathbf{Y}$, et al. Antibody responses to SARS-CoV-2 in patients of novel coronavirus disease 2019. Clin Infect Dis 2020. [Epub ahead of print] 28 de marzo de 2020. https://doi.org/10.1093/ $\mathrm{cid} / \mathrm{ciaa} 344$. 